$\$ 10,000$ Atchison, Topeka and Santa Fe Railway

Co. 4 per cent. bonds... 9,287.50

Accrued interest ....... 135.56

$\$ 10,000$ Great Northern Railway Co. 4.25 per cent. bonds ...........10,050.00

Accrued interest ......... 37.78

$\$ 10,000$ Pennsylvania Railroad Co. 4.5 per cent. bonds ...........10,487.50

Accrued interest ......... 2.50

$\$ 10,000$ Chicago, Burlington and Quincy Railroad Co. 4 per cent. bonds ... 9,350.00

Accrued interest ....... 177.78

$\$ 10,000$ Union Pacific Railroad Co. 4 per cent. bonds ........... 9,012.50

Accrued interest ........ 170.67 $\$ 10,000$ Northern Pacific Railway Co. 4 per cent. bonds ........... 9,187.50

Accrued interest ....... 37.89

$\$ 10,000$ New York Central and Hudson River Railroad Co. 3.5 per cent. bonds ............ 8,237.50

Accrued interest ....... 32.08

Dec. 20. Cash in banks as follows:

Fifth Avenue Bank of New

York ............\$1,681.34

United States Trust Com-

pany of New York .....6,692.37

$\$ 8,373.71$

Total .$\overline{\$ 111,141.58}$

SCHEDULE OF INVESTMENTS Securities Purchased

Par Value

$\$ 10,000$ Chicago and Northwestern Railway Co. general mortgage 4 per cent. bonds, due $1987 \ldots \ldots \ldots \ldots \ldots . \$ 9,425.00$

$\$ 10,000$ Atchison, Topeka and Santa Fe Railway Co. general mortgage 4 per cent. bonds, due $1995 \ldots \ldots \ldots$. 9,287.50

$\$ 10,000$ Great Northern Railway Co. first and refunding mortgage 4.25 per cent. bonds, due $1961 \ldots \ldots \ldots . .10,050.00$

$\$ 10,000$ Pennsylvania Railroad Co. consolidated mortgage 4.5 per cent. bonds, due $1960 \ldots \ldots \ldots \ldots \ldots \ldots$. . . . . 487.50

$\$ 10,000$ Chicago, Burlington and Quincy Railroad Co. general mortgage 4 per cent. bonds, due $1958 \ldots \ldots \ldots .9,350.00$

$\$ 10,000$ Union Pacific Railroad Co. first lien and refunding mortgage 4 per cent. bonds, due 2008..... 9,012.50
$\$ 10,000$ Northern Pacific Railway Co. prior lien railway and land grant 4 per cent. bonds, due $1997 \ldots \ldots \ldots .9,187.50$

$\$ 10,000$ New York Central and Hudson River Railroad Co. 3.5 per cent. bonds, due $1997 \ldots \ldots \ldots \ldots \ldots \ldots$. $8,237.50$

Appraised value of bonds received $\$ 75,037.50$ from Colburn estate ......... 25,740.00 $\$ 100,777.50$

R. S. WOODWARD,

December 20, 1916 Treasurer

\section{THE AMERICAN ASTRONOMICAL SOCIETY}

THE twentieth meeting of the American Astronomical Society was held at Columbia University, on December 26-29, 1916, in connection with the Convocation-week meeting of the American Association for the Advancement of Science. The attendance was large, forty-nine members being present, but was unevenly distributed geographically, two thirds of those present coming from the $\mathrm{New}$ England and Middle States, and only two from west of the Mississippi.

By an unusual coincidence, three of the most important communications from the standpoint of astronomy were not made at the sessions of the Astronomical Society. Professor Campbell's admirable address on "The Nebulæ", was delivered by him as retiring president of the American Association for the Advancement of Science at a general session; and the no less interesting addresses of Professor Brown, on the relations between mathematics and the physical sciences, and of Professor Leuschner, on the determination of orbits, were presented at a joint meeting of the American Mathematical Society, the Mathematical Association of America, the American Astronomical Society and Section A of the A. A. A. S.-which organizations also joined in a very enjoyable dinner on Thursday evening. As these three addresses will doubtless be published in extenso, it is of no use to summarize them here.

At the regular scientific sessions 35 papers were presented, which are here grouped according to their subject matter, rather than the order of presentation. Beginning with the mathematical and instrumental aids to investigation, Hedrick exhibited specimens of new tables for rapid interpolation of logarithmic and other tables, while Schlesinger, discussing the error arising from " 'neglected decimals," showed that this is usually 
very small; amounting, indeed, more often than not to but a single unit of the last tabulated decimal place, unless the number of tabular quantities which have been combined exceeds twenty. Plaskett showed very interesting views of the construction of the great 72-inch telescope, and of the observatory placed on Saanich Hill, Vancouver Island. The work is now practically completed except for the installation of the great mirror.

In connection with the photographic work for which such great telescopes are mainly used, F. E. Ross's paper, showing the superiority of some kinds of developer-notably "caustic hydrochinon"-in securing sharp star images, and King's which showed that, when an exposed plate is kept for months before development, the strongest images on it grow more intense, while the weakest ones fade, are of importance. The discussion. of Flint's paper on systematic errors in the determination of stellar parallax brought out an apparently general confidence in the reliability of the modern photographic determinations. In other fields, Urie described records showing that the government wireless time signals sent out from the Great Lakes station are, very consistently, about one twelfth of a second later than those sent from Arlington-this "lag", representing the time which the signals from Washington take to reach the more distant station over the telegraph lines. Russell computed that the minimum radiation visible to the eye carries energy at the rate of but one erg in forty years.

There were relatively few papers dealing with bodies in the solar system. Bauer summarized the latest results of the ocean magnetic work of the Carnegie Institution; Slocum showed a fine series of photographs illustrating the librations of the moon; Father Rigge discussed the eclipse of December 13, 1917, which will be centrally annular almost exactly at the South Pole; Very described the complications which the absorption of the earth's atmosphere introduces into the determination of the temperature of the moon; Arctowski gave the results of recent work on sun-spots, and brought out the remarkable fact that at Batavia, Java, the weather tends distinctly to be unusually rainy on days of magnetic storms-which, with other facts, falls in well with the belief that the magnetic disturbances are caused by the impact of electrically charged corpuscles on the earth's atmosphere; and W. E. Glanville described and discussed 'his observations of the zodiacal light.

As has been usual in recent years, many communications dealt with stellar astronomy. Benja- min Boss and his colleagues von Flotow and Raymond contributed six important papers on stellar distribution and drift. It was found that the brighter naked-eye stars tend to congregate, not only towards the galactic plane, but toward a subsidiary plane inclined about $50^{\circ}$ to the former; that in certain regions of this belt of bright stars there exist tendencies toward systematic motion of a type not present elsewhere; that near the south galactic pole the whiter and redder stars are, for the most part, moving in different directions; that the stars of large proper motion tend to move parallel to one or other of two mutually rectangular planes in space; that in some cases the parallaxes of these stars can be estimated with considerable accuracy on the basis of these motions, and so on. Two papers by Shapley and Pease dealt with starclusters, one giving evidence that the great cluster in Hercules is not strictly globular, but ellipsoidal, and the other announcing several important observations, especially that many of the very faint stars in the clouds which compose the Milky Way are bluish-white (which is not the case in other parts of the sky), and that it is therefore probable that the distance of these star clouds is much more than ten thousand light years. Seares (likewise from Mount Wilson photographs) finds that the number of stars per square degree in the center of the Milky Way is more than twenty times as great as near the galactic poles - a result in remarkable and still unexplained discordance with the ratio of four to one obtained at Greenwich.

Another group of communications dealt with variable and double stars. Leon Campbell exhibited the remarkably successful cooperative work of amateur observers in following the peculiar variable SS Cygni; Kunz and Stebbins reported the discovery of two new variable stars in Orion-one of them, Eta Orionis, a bright star, with variation due to eclipse. Bailey discussed the light-curves of cluster variables; Dugan gave a preliminary account of his observations on the eclipsing system $U$ Cephei, which shows a conspicuous secondary minimum; and Miss Cannon, describing the spectra of this same star, reported that the bright component was of Class $A$, and the larger but fainter one which totally eclipses it of Class $K-$ so that these two stars, though separated by little more than the diameter of either, are spectroscopically as unlike as Sirius and Arcturus; and Russell presented orbits of the visual binaries $\epsilon$ Equulei and Krueger 60-the latter the faintest and least massive star whose orbit has so far been computed.

Three important papers on nebulæ close the list. 
Van Maanen finds for the planetary nebula N.G.C. 7662 a parallax of $0^{\prime \prime} .023$, making its distance 140 light years, and its diameter about twenty times that of the orbit of Neptune; Newkirk, from a splendid series of Lick photographs, concludes that the ring nebula in Lyra has no sensible parallax or proper motion, and must be of enormously great size; and Wright, with the new Draper quartz spectrograph of the Lick Observatory, finds evidence of continuous spectrum in the extreme ultraviolet in the planetary nebulæ, and gives good reasons for attributing it to hydrogen in the gaseous state. A fourth paper, on the rotation of planetary nebulæ, had to be read by title, on account of the regretted illness of its author, Professor Campbell.

Little formal business came before the meeting, as most of this had been attended to at Swarthmore in August. A committee upon observation of variable stars was created, to cooperate with and extend the excellent work which is now being so extensively done by amateurs. A special committee constituted to consider and make a public statement upon the widely discussed "Daylight Saving Plan" reported as follows:

"1. The chief objects the daylight saving plan hopes to accomplish are: (a) to facilitate earlier rising in summer than in winter; $(b)$ to increase the hours of daylight available after the day's work for recreation or other purposes; and (c) to conserve to the nation as a whole a part of the fuel now being consumed in the production of artificial light.

“'2. The plan which has been proposed for the United States, and which has been adopted as a war measure in England, France and Germany, as well as in Holland, consists in advancing the legal time one hour during part of the summer half of the year. In the United States this amounts to a simple shift of the boundaries of existing standard time zones.

“' 3 . In order to be of real benefit, the plan must be adopted simultaneously by a large majority throughout an extended area of the United States.

"4. It is to be noted that the advantages of the plan become less as we approach the extreme southern part of the country, because the hours of daylight are more nearly the same throughout the year in lower latitudes. For this reason, this committee suggests that a modification of the proposed plan might be advisable for the extreme southern portion of the United States.

" 5 . If daylight saving is adopted, this committee recommends that, in order to obviate the in- troduction of terms that may prove confusing, the names now in use to describe standard time be continued with unchanged meaning, thus in Chicago Central Time would be used in winter, as at present, and eastern time in summer.

“6. The proposed plan involves no advantages in scientific work, nor does it entail serious disadvantages. Meteorological observers would continue the present practise of making their observations at specified Eastern Standard times throughout the country. The change in time could easily be taken into account in the preparation of tide tables and similar publications.

" 7 . The chief objections to the proposed plan that have been brought to the attention of the committee are the following:

"(a) In all civilized countries the middle of the working day is not noon, but somewhat later. Under the proposed plan it would sometimes come before noon, and usually earlier than the experience of mankind appears to have justified.

" (b) Artisans who begin work early would have to get up in the dark, thus undergoing serious inconvenience, and at times using more instead of less light, and also at some seasons requiring more fuel.

" (c) The setting back or forward of all clocks by an hour on two days in each year will involve inconvenience and annoyance.

"(d) 'Not a single scientific society or other body with expert knowledge has supported it (Nature).

"8. The committee are unanimous in regard to sections 1 to 6 above, but are not agreed as to the weight that should be attached to the disadvantages enumerated under 7. Two members, Jacoby and Schlesinger, favor the adoption of the plan as proposed, and are convinced it would be highly beneficial; a third, Poor, believes that the plan should be put into operation, but for the present as an experiment. The two remaining members, Pickering and Russell, believe that the disadvantages distinctly outweigh the advantages, and are opposed to the adoption of the daylight saving plan."

It may be added that a vote at one of the meetings of the society showed eight members in favor of the plan, seven opposed to it, and fourteen neutral.

With resolutions of thanks to Columbia University for the hospitality extended to the society, the meetings came to a close on Friday afternoon, December 29.

HENRY NoRRIS RUSSELL, Acting Secretary for the Meeting 